See discussions, stats, and author profiles for this publication at: https://www.researchgate.net/publication/344721394

\title{
Spatial and temporal shift in the factors affecting the population dynamics of Calanus copepods in the North Sea
}

Article in Global Change Biology · October 2020

DOl: $10.1111 / \mathrm{gcb} .15394$

CITATIONS

2

4 authors:

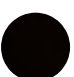

Jose Tomas Montero

Pontificia Universidad Católica de Chile

8 PUBLICATIONS 35 CITATIONS

SEE PROFILE

Sergio A Estay

Universidad Austral de Chile

78 PUBLICATIONS 1,057 CITATIONS

SEE PROFILE

Some of the authors of this publication are also working on these related projects:

A Database of the Exotic Insects of Chile View project

Project Massive defoliation in Patagonian forests View project
Ao Mauricio Lima

Pontificia Universidad Católica de Chile

122 PUBLICATIONS 8,131 CITATIONS

SEE PROFILE

Enrico L Rezende

Pontificia Universidad Católica de Chile

135 PUBLICATIONS 5,256 CITATIONS

SEE PROFILE 


\title{
Spatial and temporal shift in the factors affecting the population dynamics of Calanus copepods in the North Sea
}

\author{
José T. Montero $^{1}$ (D) | Mauricio Lima ${ }^{1}$ | Sergio A. Estay ${ }^{1,2}$ | Enrico L. Rezende ${ }^{1}$ (D)
}

${ }^{1}$ Center of Applied Ecology and Sustainability (CAPES), Facultad de Ciencias Biológicas, Pontificia Universidad Católica de Chile, Santiago, Chile

${ }^{2}$ Instituto de Ciencias Ambientales y Evolutivas, Facultad de Ciencias, Universidad Austral de Chile, Valdivia, Chile

\section{Correspondence}

José T. Montero, Center of Applied Ecology and Sustainability (CAPES), Facultad de Ciencias Biológicas, Pontificia Universidad Católica de Chile, Santiago, Chile.

Email: jomontero@uc.cl

Funding information ANID, Grant/Award Number: 1170017; CONICYT PIA/BASAL, Grant/Award Number: FB0002-2014

\begin{abstract}
The swap in abundance between two Calanus species in the North Sea during the 1980s constitutes a quintessential example of regime shift, with important ecosystemic and economic repercussions because these copepods constitute a major component of the diet of larval and juvenile cods. It is hypothesized that this transition was driven by gradual changes in primary productivity, the North Atlantic Oscillation (NAO) and sea surface temperatures (SST), and yet how these factors contribute to the population dynamics of these two species and the overall regime shift remains unclear. Here, we combine a highly resolved and spatially structured longitudinal dataset with population dynamics theory-based models to obtain a thorough and more detailed description of populations' responses to the regime shift observed in the North Sea. Our analyses highlight that this transition exhibits a clear spatial structure and involved a decoupling between the dynamics of Calanus finmarchicus and the NAO in western regions and between Calanus helgolandicus and SST in the eastern regions of the North Sea. Consequently, the observed switch in abundance between these species reflects the interaction between species-specific attributes, a well-defined spatial structure with a marked east-west axis and a decoupling between the ecological drivers and Calanus population dynamics following the shift. Succinctly, we suspect that higher water temperatures have favored $C$. helgolandicus and resulted in restrictive conditions for $C$. finmarchicus, eventually overshadowing the effects of NAO detected in historical records. Overall, our study illustrates how population dynamics theory can be successfully employed to disentangle the complex and multifactorial nature of a regime shift in response to gradually changing environmental conditions.
\end{abstract}

\section{KEYWORDS}

copepods, interspecific interaction, North Atlantic Oscillation, population dynamics, regime shift

\section{1 | INTRODUCTION}

Studies on population dynamics focus primarily in understanding why animal populations fluctuate in time and space (Berryman, 1999; Royama, 1992). A paradigmatic case involves the population dynamics of two copepod species, Calanus finmarchicus and Calanus helgolandicus, across the North Atlantic Ocean and the North Sea, which has been the focus of substantial research (Fromentin \& Planque, 1996; Melle et al., 2014; Planque \& Taylor, 1998). This system is compelling because Calanus larvae are at the bottom of the food chain and constitute a main food source for many fish species, including commercially important ones such as the cod, which has 
seen a collapse of the stocks in the 1980s (Hutchings \& Myers, 1994). Consequently, their population dynamics may have important ecosystemic and economic consequences, which is concerning because Calanus species exhibited a pronounced regime shift during the 1980s that has been attributed to changing environmental conditions (Beaugrand et al., 2009, 2014; Reid et al., 2016). Specifically, in the North Sea, populations of the predominant species $C$. finmarchicus have declined since 1970, concomitantly with an apparent increase in abundance of $C$. helgolandicus (Fromentin \& Planque, 1996; Planque \& Taylor, 1998).

While the observed responses of $C$. finmarchicus have been originally linked to the North Atlantic Oscillation (NAO; Fromentin \& Planque, 1996), whose influence seems to have been overshadowed in the late 1980 s by increasing sea surface temperatures (SST; Beaugrand, 2012; Beaugrand et al., 2014; Melle et al., 2014; Papworth et al., 2016), the ecological mechanisms underlying the yearly and long-term population dynamics of these species remain contentious and poorly understood (Ottersen et al., 2001). One hypothesis is that recruitment, growth and reproduction of $C$. finmarchicus are negatively affected by warm surface waters (Fromentin \& Planque, 1996; Hirche, 1996; Melle et al., 2014), decreasing with warm currents from the North Atlantic toward the inner North Sea during a positive NAO and increasing as cold waters flow from the Norwegian Sea to the North Sea during a negative NAO (Reid et al., 2001). Alternatively, Fromentin and Planque (1996) have proposed that changes in abundance of $C$. finmarchicus and $C$. helgolandicus could be related to primary productivity and interspecific competition. Thus, apart from the putative impact of varying water temperatures, different mechanisms have been proposed to explain the association between NAO and Calanus dynamics (see Fromentin \& Planque, 1996 and references therein): (a) changes in food availability; (b) changes in the interspecific interaction dynamics between $C$. finmarchicus and $C$. helgolandicus; (c) variation in the influx of individuals from the Faeroe-Shetland Channel to the North Sea; and (d) the reduction of deep waters of the Norwegian Sea. Multiple approaches have been employed to put these hypotheses to a test, including simple correlations, genetic algorithms (Papworth et al., 2016), spatially implicit analyses and explicit niche modeling approaches (Wilson et al., 2016). Nonetheless, results remain to a large degree inconclusive.

Importantly, none of the approaches applied population dynamics theory and the mechanistic models developed by Royama (1977, 1992), Berryman (1999) and Turchin (2003), which provide a robust framework to determine which population parameters have changed during the ecological shift, how and why. Here we attempt to bridge this gap in knowledge and address which processes might explain the population dynamics and ecological shift of these two Calanus species in both time and space. Specifically, we combined a highly resolved and spatially structured longitudinal dataset with population dynamics theory-based models to discriminate between the putative role of abiotic factors, geography, food availability and species interactions (Fromentin \& Planque, 1996). Moreover, we employed a model comparison approach that allowed us to estimate the relative weigh of the evidence favoring these alternative scenarios, opening the venue to obtain a more complete overview of the dynamics of these Calanus species across the North Sea.

\section{2 | MATERIALS AND METHODS}

\section{1 | Longitudinal data and predictor variables}

Copepod population abundance and phytoplankton color index (PCI) data have been collected by the continuous plankton recorder survey (CPR; Richardson et al., 2006) continuously since 1958. The PCl is a visual assessment of the green color of CPR samples, which constitutes an estimate of phytoplankton biomass (Batten et al., 2003; Raitsos et al., 2013). Importantly, PCl only represents the fraction of large autotrophs cells ( $>271 \mu \mathrm{m})$, so its interpretation must be taken with caution. Since both Calanus rely primarily on phytoplankton as a food source, we used the $\mathrm{PCl}$ to evaluate the influence of variation in food availability on the population dynamics of the two copepod species. It is also important to mention that the CPR data only identify to species-level stages CV-VI for C. finmarchicus and C. helgolandicus.

The data for years $1958-2017$, which is spatially structured based on the CPR standard areas (https://www.cprsurvey.org/data/ map-data/) as shown in Figure 1a, were obtained from the Sir Alister Hardy Foundation for Ocean Science (SAHFOS) with a monthly resolution. All monthly time series for each region were yearly averaged, to observe the interannual population fluctuations of the two copepods (Figure $1 \mathrm{~b}-\mathrm{g}$ ), which allows us to infer how positive and negative feedbacks operate from a mechanistic perspective. Specifically, we can estimate in a population dynamics model how parameters describing carrying capacity, intraspecific and interspecific competition and the rate of change are affected by environmental fluctuations. This approach has been widely applied to a variety of populations and discussed at length by Berryman (1999) and Royama (1977, 1981). The resulting dataset encompassed a 59-year time series of yearly averaged abundances for each North Sea CPR standard sampling areas (B1, B2, C1, C2, D1, D2) for C. finmarchicus and C. helgolandicus, as well as PCI (Figures $1 \mathrm{a}$ and 2a). Consequently, a total of 12 time series corresponding to each standard area were analyzed to evaluate the effect of the climate and productivity on the population fluctuations of the two Calanus copepods (Tables S1 and S2).

To estimate the effect of the biological and environmental exogenous factors in our longitudinal dataset, we included $\mathrm{PCI}, \mathrm{NAO}$ and SST as independent variables in our analyses. The NAO consists of a north-south climatic alteration caused by changes in the atmospheric mass pressures of Azores high and Iceland low-pressure centers (Greatbatch, 2000; Hurrell, 1995). It is considered one of the most influential climatic indices in the North Atlantic Ocean (Barnston \& Livezey, 1987), being more pronounced in winter and explaining a third of the variation of sea level pressure (SLP) in this region (Cayan, 1992; Hurrell, 1995). The NAO index employed here was calculated based on the difference in normalized SLP between 
(a)

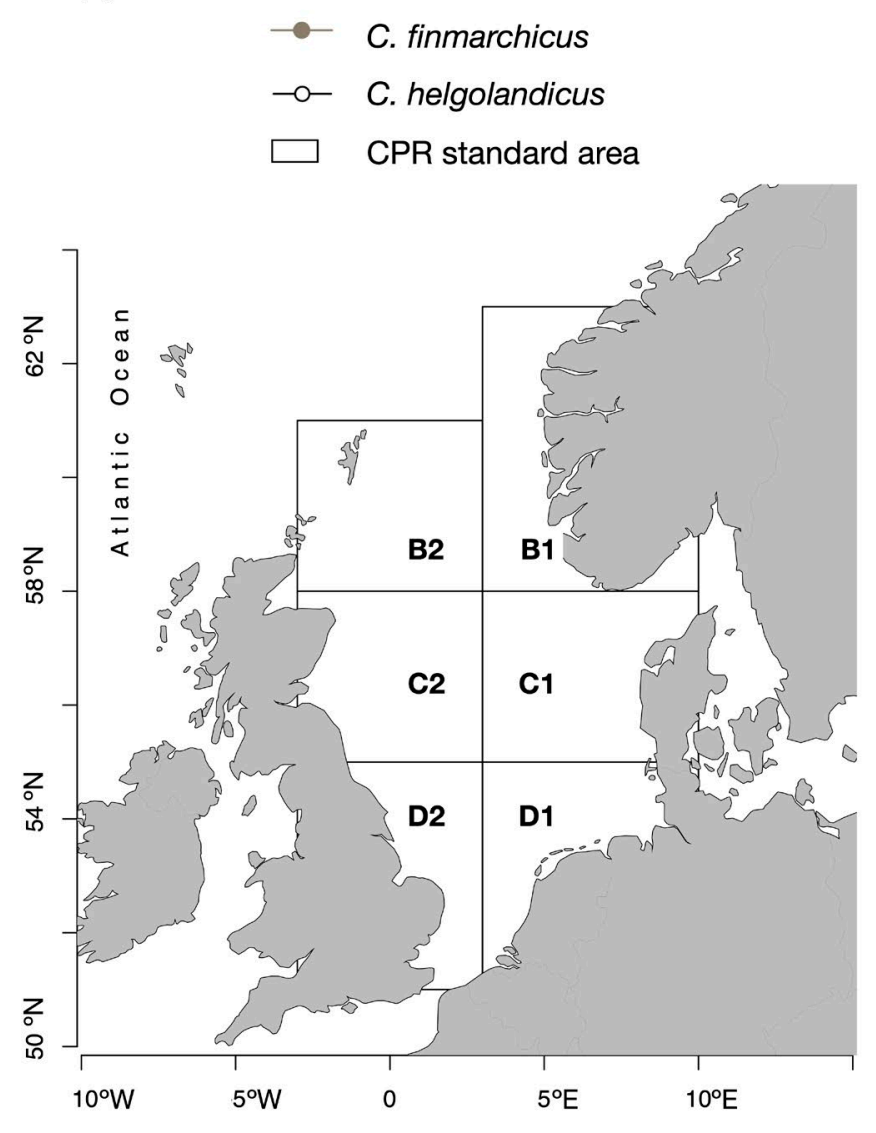

(b)

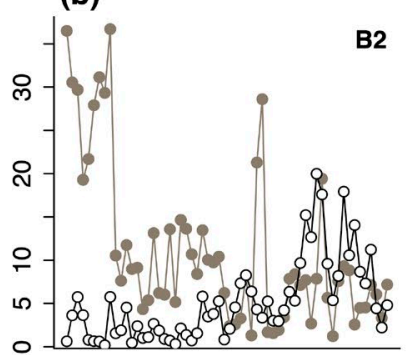

(d)
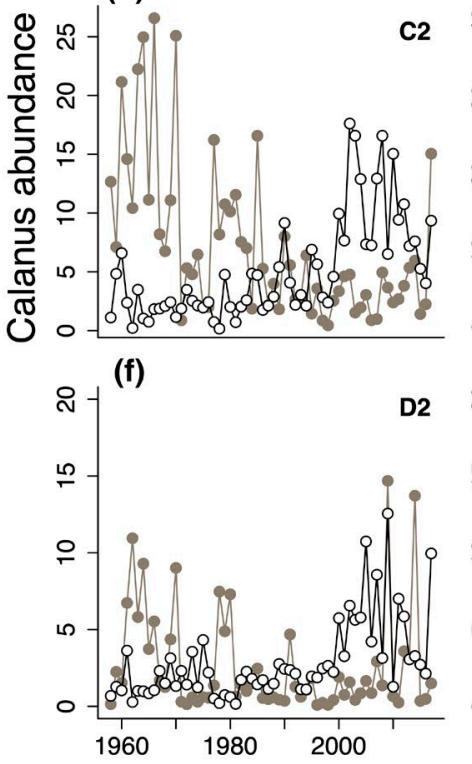

(c)

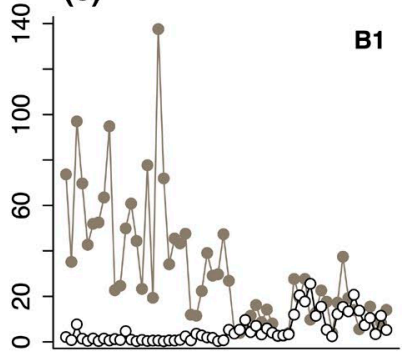

(e)

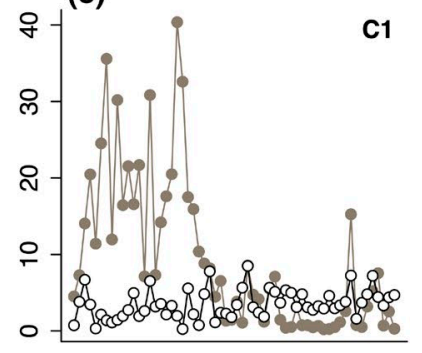

(g)

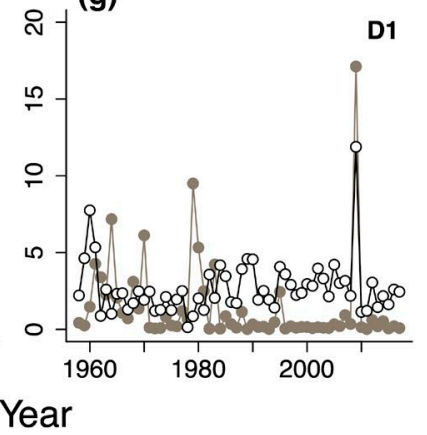

FIGURE 1 (a) Sir Alister Hardy Foundation for Ocean Science (SAHFOS) standard areas in the North Sea. (b-g) Times series of Calanus finmarchicus and Calanus helgolandicus. For clarity, panels here and in subsequent figures are ordered geographically

Azores, Portugal, and Stykkisholmur, Iceland, for the winter period between December and March (Hurrell, 1995; Figure 2b). For SST (expressed in ${ }^{\circ} \mathrm{C}$ ), which is known to influence both the abundance and spatial distribution of marine ectotherms in general (Beaugrand, 2015; Mauchline, 1998; Schmidt-Nielsen, 1990), and apparently of $C$. finmarchicus and $C$. helgolandicus in particular (Beaugrand, 2015), we obtained the time series data from the British Atmospheric Data Center (HadISST 1.1 dataset) with yearly averages for each standard area (Figures $1 \mathrm{a}$ and $2 \mathrm{~b}$; https://climatedat aguide.ucar.edu).

\section{2 | Statistical analyses}

The North Sea exhibited dramatic biophysical changes at the end of the 1980s, which have been well documented (Beaugrand, 2015; Reid et al., 2001, 2016). Because environmental forcing can cause sudden discontinuities or shifts in the parameter values of the population, as well as a spatial-temporal shift in the limiting factors (Berryman, 1999), we explicitly included a shift in limiting factors as a hypothesis in our analysis. To do so, we split the time series in two periods for each area: one from 1958 to 1986 and the other one from 1987 to 2017 to evaluate the effect of the environmental and biological fluctuation before and after the North Sea regime shift. As a result, we obtained a total of 24 separate time series (i.e., 6 areas $\times 2$ periods $\times 2$ species). Subsequently, we fitted increasingly complex population dynamics models, incorporating the contribution of exogenous variables ( $\mathrm{PCl}, \mathrm{NAO}$ and SST) and interspecific competition, and assessed their relative fit to these separate time series employing a model comparison approach. Finally, we validated the candidate models with the best fit by comparing the predicted population dynamics against the empirical data. It is important to clarify that our goal is not to find the specific mechanism behind the regime shift, which is likely multifactorial, but to investigate how this shift altered the relationship between copepod population dynamics and environmental variables both in space and time. The candidate models and validation procedures are described in detail below.

\section{3 | Model fitting}

We employed the R-function to quantify the feedback structure, which stands for the type and sign of the feedback (Berryman, 1999), of each copepod population. This function 

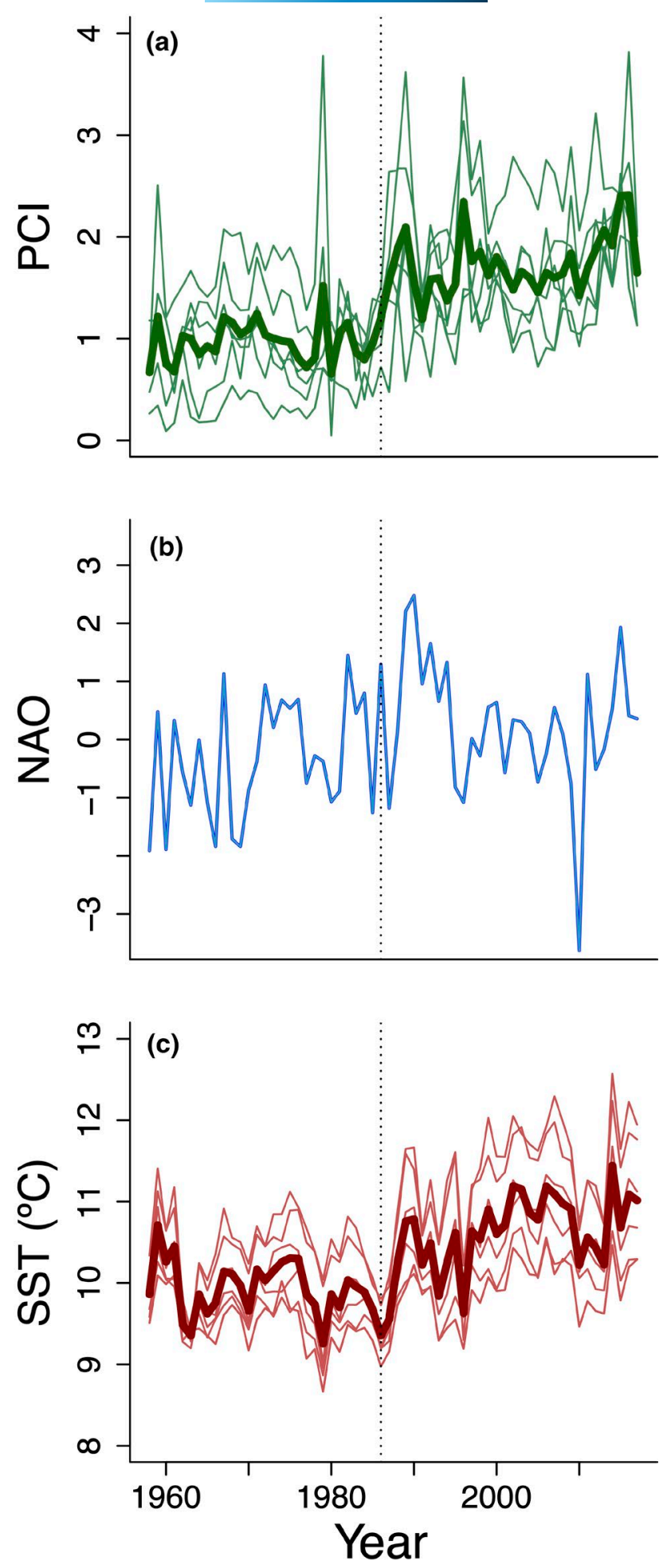

FIGURE 2 Environmental predictor time series. (a) PCI, phytoplankton color index. (b) SST, sea surface temperature $\left({ }^{\circ} \mathrm{C}\right) .(\mathrm{c})$ NAO, North Atlantic Oscillation. The thin lines represent values for each geographic area, and the thick lines the average for the North Sea. Dotted vertical line marks the regime shift in 1986

represents the population per capita rate of change and shows the process of individual survival and reproduction (Berryman, 1999), and is expressed as:

$$
R_{t}=\log \left(\frac{N_{t}}{N_{t-1}}\right)
$$

where $R_{t}$ is the realized per capita rate of change and $N$ represents the population density at time $t$ and $t-1$, expressed in years. We then performed a partial rate correlation function (PRCF; Berryman $\&$ Turchin, 2001) to identify the order of the feedback structure in all the time series. Subsequently, we used a simple model of intraspecific competition to understand how intra-population processes might affect the dynamics of both copepod species. This model corresponds to the exponential form of the discrete logistic model (Ricker, 1954), using its general version (Royama, 1992) defining the logarithmic density as:

$$
R_{t}=R_{\mathrm{m}}-\mathrm{e}^{\left(a X_{t-1}+C\right)}
$$

where $R_{\mathrm{m}}$ is the maximum rate of change in $R_{\mathrm{t}}$, a quantifies the effects of interference on individuals as density increases (Royama, 1992), with $a>1$ indicating that interference intensifies with density and $a<1$ indicating habituation to interference, and $C$ represents the impact of resource depletion, and $X_{t-1}=\log \left(N_{t-1}\right)$. For clarity, we will refer to this model in the results and discussion sections as "Ricker," when no environmental factors are included.

Using this logistic model, we fitted the R-function for each copepod species, area, and the period before (1958-1986) and after (1987-2017) the regime shift. With this approach, we can visualize potential "lateral," "vertical," and "nonlinear" effects of exogenous variables in the R-function (Royama, 1992). A lateral effect acts on the population carrying capacity through a direct or indirect effect in the resource availability, displacing the equilibrium density of the population toward the left or right, that is, a lower or higher carrying capacity, respectively ( $x$-axis, Figure 3a-f; Figure 3a1-f1). In contrast, a vertical perturbation affects the rate of change of the population independently of its density, either increasing or reducing it ( $y$-axis, Figure 3a-f; Figure 3a1-f1). Finally, a nonlinear effect reflects a combined lateral and vertical displacement of the R-function, or a change in its overall shape. These displacements could be caused by environmental changes and/or changes in the community structure of the North Sea, and their potential effects can be assessed with the inclusion of climatic or exogenous perturbations in the parameters $R_{\mathrm{m}}, C$ and $a$ (Equation 2) using the framework of Royama (1992; see Data S1 equations S1-S9).

Because both copepods have similar development times (Hansen et al., 2003), and C. finmarchicus exhibits annual or multiannual cycles (Bagoeien et al., 2012; Broms et al., 2009; Melle \& Skjoldal, 1989), we assessed the effect of the environmental conditions over the rate of change without lags in our models (Alvarez-Fernandez et al., 2012 employ a 3-month lag in their analyses, which is not possible with our dataset with an yearly resolution). With this framework, we fitted a total of 10 univariate "environmental" models (Ricker +3 environmental factors $\times 3$ possible responses) per area for each copepod species (see Data S1). Apart from the effects of exogenous perturbations, the regime shift may also alter the magnitude of interspecific 
- C. finmarchicus 0

C. helgolandicus

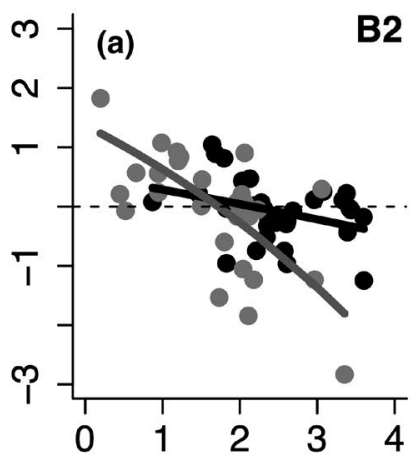

B2

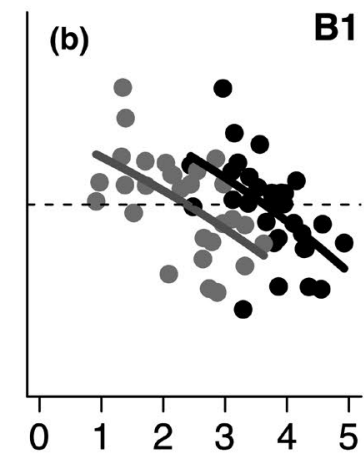

B1

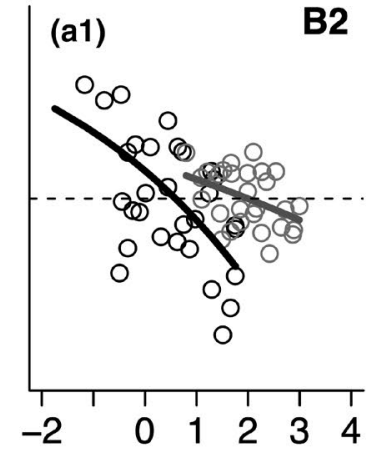

B2

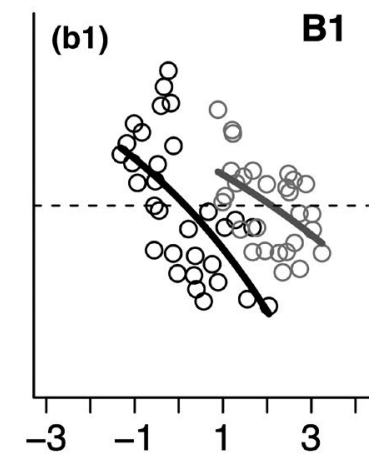

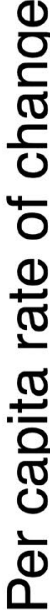
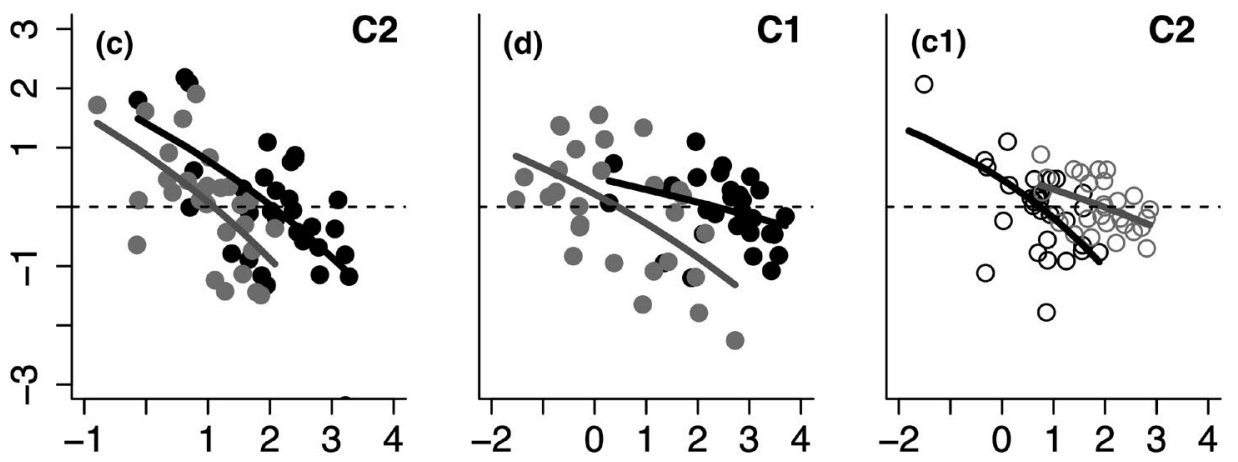

(d1)

C1
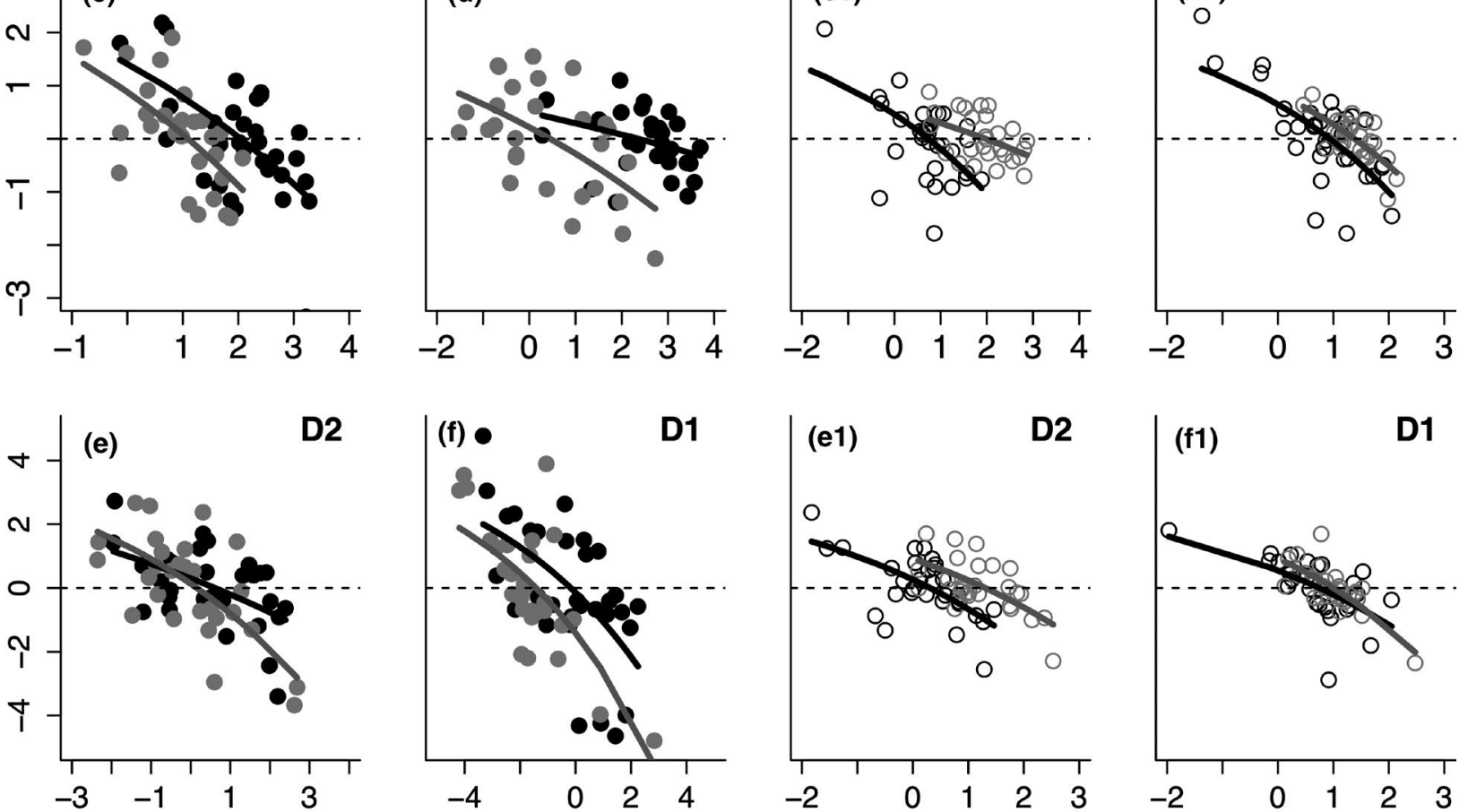
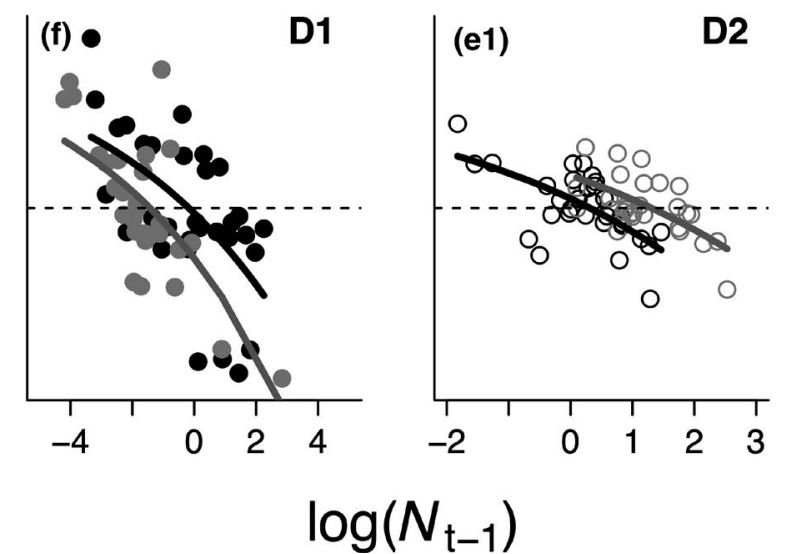

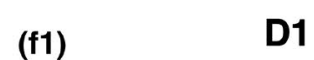

D1

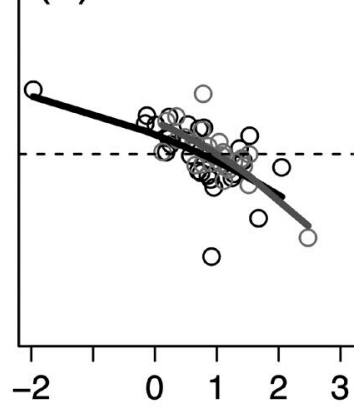

FIGURE 3 Adjusted population dynamics logistic model (Equation 2) for the R-function, for each copepod species, different geographic areas (B1-D2), and periods. (a-f) Calanus finmarchicus, (a1-f1) Calanus helgolandicus. $N_{t-1}$ : Population density at time lag $t-1$

competition (if present), which can be modeled with the logistic model as:

$$
R_{t}=R_{\mathrm{m}}-\mathrm{e}^{\left(a X_{t-1}+a_{2} X_{2 t-1}+C_{1}\right)}
$$

which corresponds to Equation (2) with the inclusion of a second species with density $X_{2 t-1}$ and competitive intensity mediated by parameter $a_{2}$. Thus, this model represents the basic feedback structure determined by both intra- and interspecific competition. Subsequently, we fit the same 10 models now including this competition effect, ultimately resulting in a total of 20 models that potentially assess, as a whole, the impact of environmental factors and interspecific competition in the dynamics of these two Calanus species.
We fit the times series before and after the shift with nonlinear regressions using the $n / s$ (nonlinear least squares) library in the $\mathrm{R}$ programing language (R Development Core Team, 2019), employing the global dataset (global model) for each Calanus species and separately for each area. These analyses are complementary since they address if the same environmental factors account for the temporal dynamics and spatial variation at different scales (i.e., within each area vs. across the entire North Sea). Models were ranked according to the second-order Akaike information criterion (AIC ${ }_{c}$, see Burnham \& Anderson, 1998 for details), and we calculated the Akaike weights $\left(w_{\mathrm{i}}\right)$ to infer the relative likelihood of each model (Burnham \& Anderson, 1998). Finally, using a multimodel inference approach (Burnham \& Anderson, 1998; Symonds \& Moussalli, 2011), we 
estimated the relative importance of each predictor across all candidate models and identified the variable(s) that might be driving the system's dynamics for each area and period by pooling models with the same environmental predictor (NAO, SST or PCI) and adding their $w_{i}$. This quantifies the probability that this predictor is part of the best model irrespective of the nature of the response (i.e., vertical, lateral or nonlinear). We fixed parameter $R_{\mathrm{m}}$ to the maximum observed $R_{t}$ in the time series of each species, to avoid convergence problems when fitting the models. It is important to notice that in the case of nonlinear models the $R^{2}$ calculated for each model cannot be used to determine goodness of fit or model performance (Kvalseth, 1983), and consequently we focused primarily in the $\mathrm{AIC}_{\mathrm{c}}$ and $\mathrm{w}_{\mathrm{i}}$ results.

\section{4 | Validation}

We tested how well the model with the best fit actually performed by contrasting its predicted values against the observed Calanus abundance for all areas and both periods (1958-1986 and 1987-2017), employing the one step-ahead forecasting equation (Berryman, 1999):

$$
E\left[N_{t}\right]=N_{t-1} \mathrm{e}^{R}
$$

where $E\left[N_{t}\right]$ represents the expected abundance of the population at time $t, N_{t-1}$ the previous abundance and $R$ the per capita rate of change predicted using the models with the lowest $\mathrm{AIC}_{\mathrm{c}}$ for each area and period (see Data S1). Observed and predicted dynamics were compared using the root mean squared deviation (RMSD) of the difference between observed and predicted values as:

$$
\mathrm{RMSD}=\sqrt{\frac{1}{n-1} \sum_{i=1}^{n}\left(P_{i}-O_{i}\right)^{2}}
$$

where $O_{i}$ is the observed and $P_{i}$ is predicted abundance. The RMSD shows the deviation of the predicted respect to the observed values, expressed in the same unit as the variable under test (Gauch et al., 2003; Kobayashi \& Salam, 2000). In addition, we performed a Pearson's correlation between the observed and predicted abundances.

\section{3 | RESULTS}

First-order negative feedback was a key component of the per capita rate of change in these copepod species for all areas and periods, evidenced by the strong lag $t-1$ of the PRCF performed to all time series (Table S3). This result suggests that the use of the discrete exponential Ricker model at time lag $t-1$ is adequate in all cases, and that the population fluctuation of both species is largely driven by its internal feedback dynamics. Moreover, the logistic model fitted to time series of both copepod species in different areas and periods (Equation 2) clearly identifies changes due to the regime shift and suggests, nuances aside, a lateral displacement of the R-function for both species in most areas of the North Sea, with a left shift for $C$. finmarchicus and a right shift for $C$. helgolandicus (Figure 3 ). This implies, respectively, a reduction and an increase in the environmental carrying capacity for each species. These responses are more pronounced toward the Northwest, where changes in abundances are clearly stronger (Figures 1 and 3).

The global models pooling abundance data of all areas reveal a clear change in the factors affecting the dynamics of $C$. finmarchicus in the North Sea after the regime shift (Table 1). This result is shown by the cumulative $w_{i}$ for each environmental predictor, where the NAO has a $97.6 \%$ of probability to be included in the best model before the regime shift and seems to no longer have an impact on its dynamics after the shift (Table 1; Table S7 for detailed model parameters and statistics). In contrast, SST seems to govern the dynamics of $C$. helgolandicus both before and after the regime shift (Table 1). Taken together, analyses with the global dataset show that the dynamics of both Calanus species are associated with different environmental factors and, interestingly, that the regime shift involved a qualitative change in the association between environmental variation and population dynamics for $C$. finmarchicus but not necessarily for C. helgolandicus (Table 1). More specifically, it seems that the drop in abundance of $C$. finmarchicus after 1986 was accompanied by a decoupling of its population dynamics from the NAO, whereas the spatial and temporal variation in abundance in $C$. helgolandicus apparently reflects thermal constraints across the whole region.

Interestingly, our models fitted separately for each area partly support the general patterns observed in the global analyses but also highlight some important differences primarily after the regime shift (Table 2). For $C$. finmarchicus, $\mathrm{PCl}$ and SST were included in the models with the best fit according to the global analyses (cumulative $w_{\mathrm{i}}=56.2 \%$ and $39.9 \%$, respectively; Table 1 ), whereas at the local scale Ricker or NAO were the best models in five out of six areas (Figure 4). These results suggest, therefore, that variation in $\mathrm{PCl}$ and $\mathrm{NAO}$ account predominantly for differences in abundance of $C$. finmarchicus

TABLE 1 Cumulative Akaike information criterion weights for Calanus finmarchicus and Calanus helgolandicus global models. The models with the highest support, according to Akaike weights, are highlighted in bold

\begin{tabular}{llcc} 
& & \multicolumn{2}{c}{ Cumulative Akaike weights } \\
\cline { 3 - 4 } Species & Model & $1958-1986$ & $1987-2017$ \\
\hline C. finmarchicus & Ricker & $0 \%$ & $4.7 \%$ \\
& Ricker + PCl & $1.4 \%$ & $56.2 \%$ \\
& Ricker + SST & $0 \%$ & $39.9 \%$ \\
& Ricker + NAO & $98.5 \%$ & $2.2 \%$ \\
\hline \multirow{3}{*}{ C. helgolandicus } & Ricker & $0 \%$ & $0 \%$ \\
& Ricker + PCI & $0 \%$ & $0 \%$ \\
& Ricker + SST & $100 \%$ & $100 \%$ \\
& Ricker + NAO & $0 \%$ & $0 \%$ \\
\hline
\end{tabular}

Abbreviations: NAO, North Atlantic Oscillation; $\mathrm{PCl}$, phytoplankton color index; SST, sea surface temperature; 
TABLE 2 Cumulative Akaike information criterion weights for the models of each area, period and species. Models supporting an association between environmental variables and population dynamics are shown in bold, otherwise the local scale Ricker function provides the best fit

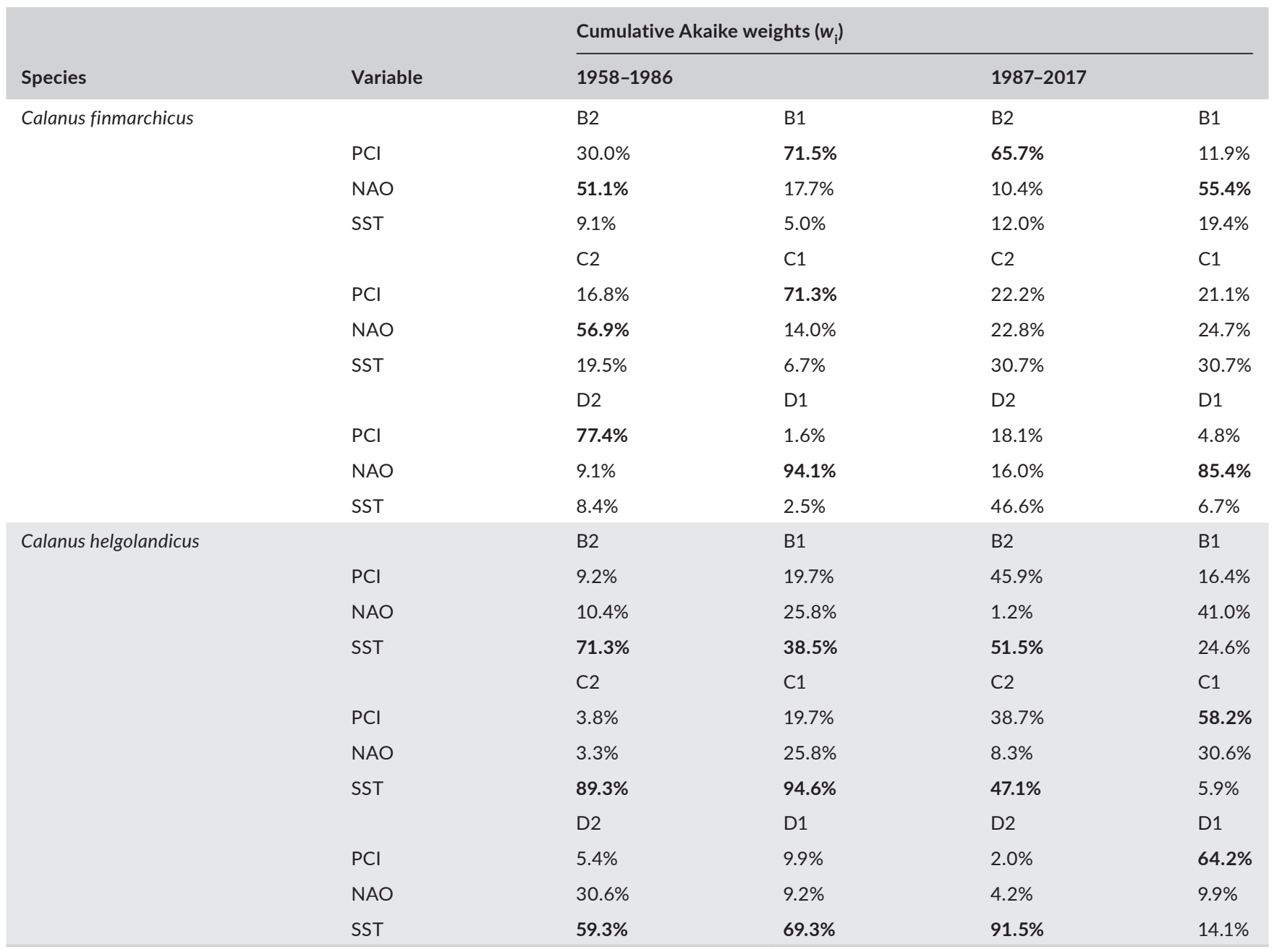

Abbreviations: NAO, North Atlantic Oscillation; PCI, phytoplankton color index; SST, sea surface temperature.

across areas, and that the decoupling of NAO and the population dynamics occurred primarily in the areas B2-D2 (Figure 4a-f). In contrast, for $C$. helgolandicus global analyses support a predominant role of SST after the regime shift that reflects, according to analyses on a regional basis, strong effects in the same areas (Figure 4a1-f1). These results indicate that the regime shift observed around 1987 exhibits a clear spatial structure and involved a decoupling between the dynamics of C. finmarchicus and the $\mathrm{NAO}$ in western areas and $\mathrm{PCl}$ in the east (B1D1) and between C. helgolandicus and SST in the eastern areas (B1-D1) of the North Sea (Figure 4).

Interspecific interaction models provide partial support for interaction in some of the areas (see Data S1). According to $\mathrm{AIC}_{\mathrm{c}}$, inclusion of an interaction component improved the models for $C$. finmarchicus in area B2 and C2, respectively, before and after the regime shift (Tables S5, S8 and S9). For $C$. helgolandicus, the interspecific interaction models exhibited lower $\mathrm{AIC}_{\mathrm{c}}$ values in areas B1, C1 and D2 before the regime shift, and only in area D2 following the shift. These results reflect the multifactorial nature of responses: because $\mathrm{PCI}, \mathrm{NAO}$ and SST effects on the population dynamics differ between the two Calanus species, the potential contribution of interspecific interactions is also predicted to vary across periods and areas. Notably, $C$. finmarchicus seemed to have an impact on the dynamics of $C$. helgolandicus before the regime shift, when it was the prevalent species in most areas (Figure $1 \mathrm{~b}-\mathrm{g}$ ).

\subsection{Model predictions and performance}

The one step-ahead predictions using the models with the lowest AIC (Figure 4; Tables S8-S11) for each copepod species were fairly accurate, and captured the general dynamics of both copepods across the North Sea. Overall, C. helgolandicus models performed better than for $C$. finmarchicus, capturing some of the peaks and the overall dynamic for all areas before and after the regime shift (Figure 4). For $C$. finmarchicus, the models failed to predict the most extreme peaks of abundance, whereas for $C$. helgolandicus the model adequately predicted some of the peaks after the regime shift (Figure 4). 
C. finmarchicus

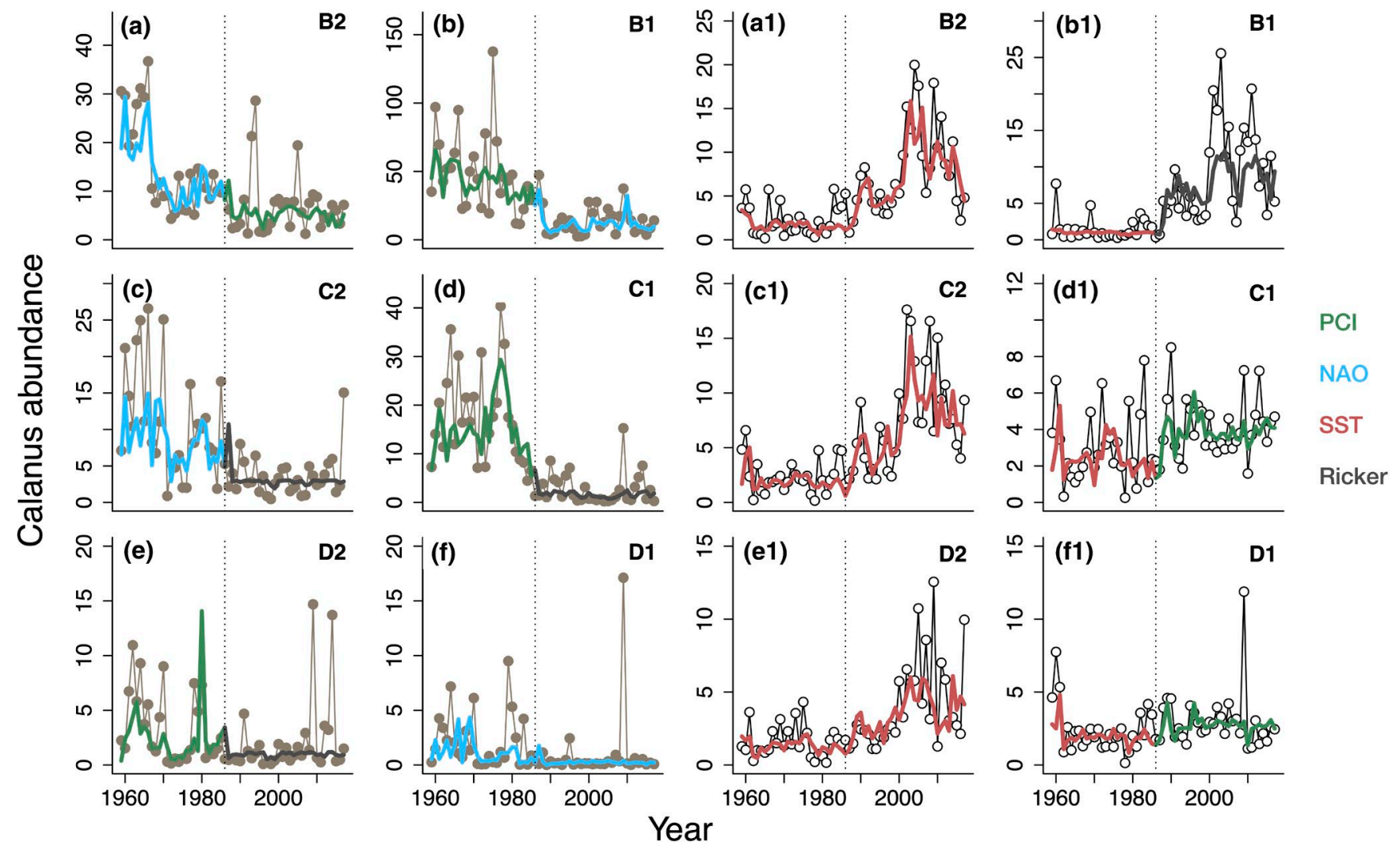

FIGURE 4 Predictions for each standard area before and after the regime shift employing the model with the lowest Akaike information criterion. Solid lines correspond to the predictions matching the model explanatory variable with the best fit for each area and period (green $=\mathrm{PCl}$, blue $=\mathrm{NAO}$, red $=\mathrm{SST}$ and black = Ricker). (a-f) Calanus finmarchicus, (a1-f1) Calanus helgolandicus. The support for these models, expressed as the cumulative $w_{\mathrm{i}}$, is provided in Table 2. Dotted vertical line marks the regime shift in 1986

\section{4 | DISCUSSION}

Here we provide a simple and coherent way to study the population dynamics of $C$. finmarchicus and $C$. helgolandicus, and reveal a scenario in which different environmental factors affect these species across space and time (Figure 4; Table 2). Results show that the population equilibrium point varies as a function of the interaction between population density (Figure 3 ) and environmental conditions (Figure 4). Our analyses highlight that changes in $\mathrm{PCl}, \mathrm{NAO}$ and SST at the end of the 1980s (Figure 2) indeed resulted in a qualitative swap in the environmental drivers affecting the population dynamics and interaction of the Calanus species and a true regime shift in the North Sea (Beaugrand, 2004, 2015; Reid et al., 2001, 2016). This general picture emerges from the comparison between results of global models (Table 1 ), in which variation in population dynamics includes both a temporal and a spatial component-that is, population size varies in time but also across areas with different environmental characteristics-versus local models where fluctuations in abundance are contrasted against environmental drivers within a limited area, ignoring what occurs in adjacent areas (Table 2). Particularly, C. finmarchicus responds to the NAO variations before the regime shift in our global model, and to $\mathrm{PCl}$ and/ or SST after the shift (Table 1), evidencing a space-time decoupling between the dynamics of $C$. finmarchicus and NAO primarily in the western regions (Table 2; Figure 4). On the other hand, the global models for $C$. helgolandicus suggested no change in the limiting factors before and after the regime shift (Table 1), but when we looked at the area models, the limiting factor shifted in areas C1 and $\mathrm{D} 1$ to be driven by $\mathrm{PCl}$. Consequently, the overall dynamics of Calanus species observed in the North Atlantic can be decomposed into three broad interacting components. First, differences between the two species in the environmental factors modulating their population dynamics, with fluctuations in $C$. finmarchicus being modulated primarily by variation in $\mathrm{NAO}$ and $\mathrm{PCl}$ and in C. helgolandicus by SST (Table 1). Second, temporal trends exhibiting a well-defined spatial structure, with marked differences between eastern and western regions (Figure 4a-f). And third, a general decoupling between the environmental drivers that accounted for the historical dynamics of $C$. finmarchicus, which suggest a true shifting limiting factor (sensu Berryman, 1999), while for $C$. helgolandicus responses seem to reflect a lateral perturbation effect (Royama, 1992) (Table 2; Figure 4a1-f1).

Our results support previous studies in this system and provide a more nuanced and detailed understanding of the multifactorial nature of the regime shift observed in the North Sea. The dynamic of $C$. helgolandicus seemed to be affected mainly 
by changes in SST before and after the regime shift, emphasizing how warming waters have favored this species following the regime shift and confirming that $C$. helgolandicus has a preference for warmer waters than C. finmarchicus (Bonnet et al., 2005). Accordingly, Beaugrand $(2012,2015)$ suggested that higher isotherms in the North Sea drove the ecosystem transition that ultimately resulted in the decline of $C$. finmarchicus and increase in C. helgolandicus populations. Similarly, the temporal decoupling of NAO and $C$. finmarchicus dynamics is consistent with analyses by Kimmel and Hameed (2008), where the correlation between these variables after the regime shift was weak, with NAO no longer explaining the variability of the population in the North Sea. Interestingly, this decoupling occurred primarily in western regions (Figure $4 a, c, e)$, emphasizing the importance of spatial variation on population dynamics (Berryman, 1999). As for $\mathrm{PCl}$, it was negatively correlated with $C$. finmarchicus in all models, which is counterintuitive because this species feeds on phytoplankton. We speculate that this reflects an underlying change in phytoplankton composition and a reduction in diatoms, which is the main food source for juvenile life stages (Castellani et al., 2008) because the annual increase in $\mathrm{PCl}$ observed during the studied period is at odds with the decreasing abundance of dinoflagellates and diatoms reported in the North Sea (Leterme et al., 2008).

Our population dynamics models provide further insights into the determinants of fluctuations in population size of both Calanus species. The strong first-order negative feedback observed in the regulation of $C$. finmarchicus and $C$. helgolandicus suggests that intraspecific competition is a crucial process on the population regulation of these copepods across all regions, before and after the regime shift (Table S3). Accordingly, Ohman and Hirche (2001) demonstrated that the per capita mortality rate is density-dependent for this oceanic plankton. For example, the mortality rate of $C$. finmarchicus eggs is a function of the number of adults and younger females, which are factors that can explain the feedback mechanisms. Also, Kimmel and Hameed (2008) showed the importance of $C$. finmarchicus robust year-to-year connectivity, as seen in the stable first-order negative feedback by the PRCF. Even though there is evidence of external climatic forces driving the population of the two copepods, an essential component of the population fluctuation is only driven by the internal processes as first-order negative feedback. With regard to interspecific interactions, our analyses provide only circumstantial evidence that this process is taking place and suggest that intraspecific competition and extrinsic environmental factors such as NAO and SST are more relevant driving the changes in abundance of both species across the North Sea.

Overall, here we demonstrate the significance of intraspecific competition in the population dynamics using a simple logistic model combined with the limiting factor principle described in great detail by Berryman (1999). Results show that the regime shift observed around 1987 exhibits a clear spatial structure and involved a decoupling between the dynamics of $C$. finmarchicus and the NAO in western areas (B2-D2)-that is, a true shifting limiting factor process-and a lateral perturbation effect caused by higher SST for
C. helgolandicus in the eastern areas of the North Sea (B1-D1). In spite of our detailed analysis, it is still a challenge to fully understand the reasons for the decoupling between these copepods' dynamics and some environmental variables across the different regions of the North Sea, particularly for the NAO effect. And while observed trends do not imply causation, it seems that higher SST may have triggered the ecological shift in abundance of Calanus species, restricting the range of favorable environmental conditions for coldadapted $C$. finmarchicus and contributing to the colonization of new areas by $C$. helgolandicus. Whether warmer temperatures would drive further increases in abundance of $C$. helgolandicus remains an open question with important ecological and commercial consequences.

\section{ACKNOWLEDGEMENTS}

We thank SAHFOS for supplying access to the continuous plankton recorder datasets and David Johns for rapidly supplying the requested data, and the extensive feedback provided by the subject editor and two anonymous reviewers that has substantially contributed to the quality of the final draft. This work was funded by grant ANID PIA/BASAL FB0002. E.L. Rezende was partly funded by FONDECYT grant 1170017

\section{DATA AVAILABILITY STATEMENT}

The data that support the findings of this study are available in the supplementary material of this article.

\section{ORCID}

José T. Montero iD https://orcid.org/0000-0002-8212-2807

Enrico L. Rezende iD https://orcid.org/0000-0002-6245-9605

\section{REFERENCES}

Alvarez-Fernandez, S., Lindeboom, H., \& Meesters, E. (2012). Temporal changes in plankton of the North Sea: Community shifts and environmental drivers. Marine Ecology Progress Series, 462, 21-38. https:// doi.org/10.3354/meps09817

Bagoeien, E., Melle, W., \& Kaartvedt, S. (2012). Seasonal development of mixed layer depths, nutrients, chlorophyll and Calanus finmarchicus in the Norwegian Sea - A basin-scale habitat comparison. Progress in Oceanography, 103, 58-79. https://doi.org/10.1016/j. pocean.2012.04.014

Barnston, A. G., \& Livezey, R. (1987). Classification, seasonality and persistence of low-frequency atmospheric circulation patterns. Monthly Weather Review, 115, 1083-1126. https://doi.org/10.1175/15200493(1987)115<1083:CSAPOL > 2.0.CO;2

Batten, S. D., Walne, A. W., Edwards, M., \& Groom, S. B. (2003). Phytoplankton biomass from continuous plankton recorder data: An assessment of the phytoplankton colour index. Journal of Plankton Research, 7, 697-702. https://doi.org/10.1093/plankt/25.7.697

Beaugrand, G. (2004). The North Sea regimen shift: Evidence, causes, mechanism and consequences. Progress in Oceanography, 60, 245-262.

Beaugrand, G. (2012). Unanticipated biological changes and global warming. Marine Ecology Progress Series, 445, 293-301. https://doi. org/10.3354/meps09493

Beaugrand, G. (2015). Marine biodiversity, climatic variability and global change. Routledge. Earthscan Ocean, 474 pp.

Beaugrand, G., Goberville, E., Luczak, C., \& Kirby, R. R. (2014). Marine biological shifts and climate. Proceedings of the Royal Society $B$ : 
Biological Sciences, 281(1783), 20133350. https://doi.org/10.1098/ rspb.2013.3350

Beaugrand, G., Luczak, C., \& Edwardsz, M. (2009). Rapid biogeographical plankton shifts in the North Atlantic Ocean. Global Change Biology, 15, 1790-1803. https://doi.org/10.1111/j.1365-2486. 2009.01848.x

Berryman, A. (1999). Principles of population dynamics and their application (p. 243). Stanley Thornes Publishers Ltd.

Berryman, A., \& Turchin, P. (2001). Identifying the density-dependent structure underlying ecological time series. Oikos, 92, 265-270. https://doi.org/10.1034/j.1600-0706.2001.920208.x

Bonnet, D., Richardson, A., Harris, R., Hirst, A., Beaugrand, G., Edwards, M., Ceballos, S., Diekman, D., Lopez-Urrutia, A., Valdes, L., Carlotti, F., Molinero, J. C., Weikert, H., Greve, W., Lucic, D., Albaina, A., DalyYahia, N., Umani, S. F., Miranda, A., ... Fernandez de Puelles, M. L. (2005). An overview of Calanus helgolandicus ecology in European waters. Progress in Oceanography, 65, 1-53. https://doi.org/10.1016/j. pocean.2005.02.002

Broms, C., Melle, W., \& Kaartvedt, S. (2009). Oceanic distribution and lifecycle of Calanus species in the Norwegian Sea and adjacent waters. Deep Sea Research Part II, 56, 1910-1921. https://doi.org/10.1016/j. dsr2.2008.11.005

Burnham, K. P., \& Anderson, D. R. (1998). Model selection and multimodel inference. A practical information-theoretic approach (2nd ed.). Springer-Verlag.

Castellani, C., Irigoien, X., Mayor, D. J., Harris, R. P., \& Wilson, D. (2008). Feeding of Calanus finmarchicus and Oithona similis on the microplankton assemblage in the Irminger Sea, North Atlantic. Journal of Plankton Research, 30, 1059-1116. https://doi.org/10.1093/plankt/fbn074

Cayan, D. R. (1992). Latent and sensible heat flux anomalies over the northern oceans: The connection to monthly atmospheric circulation. Journal of Climate, 5, 354-369. https://doi.org/10.1175/15200442(1992)005<0354:LASHFA>2.0.CO;2

Fromentin, J. M., \& Planque, B. (1996). Calanus and environment in the eastern North Atlantic. 2. Influence of the North Atlantic Oscillation on C. finmarchicus and C. helgolandicus. Marine Ecology Progress Series, 134, 111-118.

Gauch, H. G., Hwang, J. T. G., \& Fick, G. W. (2003). Model evaluation by comparison of model-based predictions and measured values. Agronomy Journal, 95(6), 1442-1446. https://doi.org/10.2134/agron j2003.1442

Greatbatch, R. J. (2000). The North Atlantic Oscillation. Stochastic Environmental Research and Risk Assessment, 14, 213-242. https://doi. org/10.1007/s004770000047

Hansen, B. W., Marker, T., Andreassen, P., Arashkewich, E., Carlotti, F., Lindeque, P., Tande, K. S., \& Wagner, M. (2003). Differences in life-cycle traits of Calanus finmarchicus originating from $60^{\circ} \mathrm{N}$ and $69^{\circ} \mathrm{N}$, when reared in mesocosms at $69^{\circ} \mathrm{N}$. Marine Biology, 142, 877893. https://doi.org/10.1007/s00227-002-1004-5

Hirche, H. J. (1996). Diapauses in the marine copepod, Calanus finmarchicus - A review. Ophelia, 44, 129-143.

Hurrell, J. W. (1995). Decadal trends in the North Atlantic Oscillation: Regional temperatures and precipitations. Science, 269, 676-679. https://doi.org/10.1126/science.269.5224.676

Hutchings, J. A., \& Myers, R. A. (1994). What can be learned from the collapse of a renewable resource? Atlantic cod, Gadus morhua, of Newfoundland and Labrador. Canadian Journal of Fisheries and Aquatic Sciences, 51, 2126-2146. https://doi.org/10.1139/f94-214

Kimmel, G., \& Hameed, S. (2008). Update on the relationship between the North Atlantic Oscillation and Calanus finmarchicus. Marine Ecology Progress Series, 366, 111-117. https://doi.org/10.3354/meps07523

Kobayashi, K., \& Salam, M. U. (2000). Comparing simulated and measured values using mean squared deviation and its components. Agronomy Journal, 92(2), 345. https://doi.org/10.1007/s100870050043
Kvalseth, T. O. (1983). Note on the $\mathrm{R}^{2}$ measure of goodness of fit for nonlinear models. Bulletin of the Psychonomic Society, 21, 79-80. https:// doi.org/10.3758/BF03329960

Leterme, S. C., Pingree, R. D., Skogen, M. D., Seuront, L., Reid, P. C., \& Attrill, M. J. (2008). Decadal fluctuations in North Atlantic water inflow in the North Sea between 1958-2003: Impacts on temperature and phytoplankton populations. Oceanologia, 50(1), 59-72.

Mauchline, J. (1998). The biology of calanoid copepods. Academic Press.

Melle, W., Runge, J., Head, E., Plourde, S., Castellani, C., Licandro, P., Pierson, J., Jonasdottir, S., Johnson, C., Broms, C., Debes, H., Falkenhaug, T., Gaard, E., Gislason, A., Heath, M., Niehoff, B., Nielsen, T. G., Pepin, P., Stenevik, E. K., \& Chust, G. (2014). The north Atlantic ocean as habitat for Calanus finmarchicus: Environmental factors and life history traits. Progress Oceanography, 129, 244-284. https://doi. org/10.1016/j.pocean.2014.04.026

Melle, W., \& Skjoldal, H. R. (1989). Zooplankton reproduction in the Barents Sea: Vertical distribution of eggs and nauplii of Calanus finmarchicus in relation to spring phytoplankton development. In J. S. Ryland \& P. Tyler (Eds.), Reproduction, genetics and distributions of marine organisms (pp. 137-145). Copenhagen: Olsen \& Olsen.

Ohman, M. D., \& Hirche, H. J. (2001). Density-dependent mortality in an oceanic copepod population. Nature, 412, 638-641. https://doi. org/10.1038/35088068

Ottersen, G. O., Planque, B., Belgrano, A., Post, E., Reid, P. C., \& Stenseth, N. C. (2001). Ecological effects of the North Atlantic Oscillation. Oecologia, 128, 1-14. https://doi.org/10.1007/s0044 20100655

Papworth, D. J., Marini, S., \& Conversi, A. (2016). A novel, unbiased analysis approach for investigating population dynamics: A case study on Calanus finmarchicus and its decline in the North Sea. PLoS One, 11, 1-26. https://doi.org/10.1371/journal.pone.0158230

Planque, B., \& Taylor, A. H. (1998). Long-term changes in zooplankton and the climate of the North Atlantic. ICES Journal of Marine Science, 55, 644-654. https://doi.org/10.1006/jmsc.1998.0390

R Development Core Team. (2019). R: A language and environment for statistical computing. Version 3.5.3. R Foundation for Statistical Computing.

Raitsos, D. E., Walne, A., Lavender, S. J., Licandro, P., Reid, P. C., \& Edwards, M. (2013). A 60-year ocean colour data set from the continuous plankton recorder. Journal of Plankton Research, 35, 158-164. https://doi.org/10.1093/plankt/fbs079

Reid, P. C., Borges, M. D., \& Svendsen, E. (2001). A regime shift in the North Sea circa 1988 linked to changes in the North Sea fishery. Fisheries Research, 50, 163-171.

Reid, P. C., Hari, R. E., Beaugrand, G., Livingstone, D. M., Marty, C., Straile, D., Barichivich, J., Goberville, E., Adrian, R., Aono, Y., Brown, R., Foster, J., Groisman, P., Hélaouët, P., Hsu, H.-H., Kirby, R., Knight, J., Kraberg, A., Li, J., ... Zhu, Z. (2016). Global impacts of the 1980s regime shift. Global Change Biology, 22, 682-703. https://doi. org/10.1111/gcb.13106

Richardson, A. J., Walne, A. W., John, A. W. G., Jonas, T. D., Lindley, J. A., Sims, D. W., Stevens, D., \& Witt, M. (2006). Using continuous plankton recorder data. Progress Oceanography, 68, 27-74. https:// doi.org/10.1016/j.pocean.2005.09.011

Ricker, W. E. (1954). Stock and recruitment. Journal of the Fisheries Research Board of Canada, 11, 559-623. https://doi.org/10.1139/ f54-039

Royama, T. (1977). Population persistence and density dependence. Ecological Monographs, 47, 1-35. https://doi.org/10.2307/1942222

Royama, T. (1981). Fundamental concepts and methodology for the analysis of animal population dynamics, with particular reference to univoltine species. Ecological Monographs, 51, 473-493. https://doi. org/10.2307/2937325

Royama, T. (1992). Analytical population dynamics. Chapman \& Hall. 
Schmidt-Nielsen, K. (1990). Animal physiology: Adaptation and environment. Cambridge University Press.

Symonds, M. R. E., \& Moussalli, A. A. (2011). Brief guide to model selection, multimodel inference and model averaging in behavioural ecology using Akaike's information criterion. Behavioral Ecology and Sociobiology, 65, 13-21. https://doi.org/10.1007/s00265-0101037-6

Turchin, P. (2003). Complex population dynamics: A theoretical/empirical synthesis. Princeton University Press.

Wilson, R. J., Heath, M. R., \& Speirs, D. C. (2016). Spatial modeling of Calanus finmarchicus and Calanus helgolandicus: Parameter differences explain differences in biogeography. Frontiers in Marine Science, 3, 157. https://doi.org/10.3389/fmars.2016.00157

\section{SUPPORTING INFORMATION}

Additional supporting information may be found online in the Supporting Information section.

How to cite this article: Montero JT, Lima M, Estay SA,

Rezende EL. Spatial and temporal shift in the factors affecting the population dynamics of Calanus copepods in the North Sea. Glob Change Biol. 2020;00:1-11. https://doi. org/10.1111/gcb.15394 